\title{
The Promise of Anti-idiotype Revisited
}

\author{
Heinz Kohler ${ }^{1 *}$, Anastas Pashov ${ }^{2}$ and Thomas Kieber-Emmons ${ }^{3}$ \\ ${ }^{1}$ Department of Microbiology and Immunology, University of Kentucky, Lexington, KY, United States, ${ }^{2}$ Stephan Angelov \\ Institute of Microbiology, Bulgarian Academy of Sciences, Sofia, Bulgaria, ${ }^{3}$ Department of Pathology, Winthrop P. Rockefeller \\ Cancer Institute, University of Arkansas for Medical Sciences, Little Rock, AR, United States
}

The promise of idiotype-based therapeutics has been disappointing forcing a new look at the concept and its potential to generate an effective approach for immunotherapy. Here, the idiotype network theory is revisited with regard to the development of efficacious anti-idiotype vaccines. The experience of polyclonal anti-Idiotype reagents in animal models as well as an understanding of the immune response in humans lends to the proposition that polyclonal anti-ldiotype vaccines will be more effective compared to monoclonal-based anti-Idiotype vaccines. This novel strategy can be adapted in Biotech-standard production of therapeutic antibodies.

\section{OPEN ACCESS}

Edited by:

Roberto S. Accolla

University of Insubria, Italy

Reviewed by:

Yvonne Paterson,

University of Pennsylvania,

United States

Wayne Robert Thomas,

Telethon Kids Institute, Australia

*Correspondence:

Heinz Kohler

heinz.kohler@uky.edu

Specialty section:

This article was submitted to

Vaccines and Molecular Therapeutics,

a section of the journal

Frontiers in Immunology

Received: 10 February 2019

Accepted: 26 March 2019

Published: 12 April 2019

Citation:

Kohler $\mathrm{H}$, Pashov $\mathrm{A}$ and

Kieber-Emmons T (2019) The Promise

of Anti-idiotype Revisited.

Front. Immunol. 10:808.

doi: 10.3389/fimmu.2019.00808
Keywords: idiotype, polyclonal, vaccines, polyreactive, multi-epitope binding, therapeutic, mimetic

\section{INTRODUCTION}

The strategy of using anti-idiotype (anti-Id) antibodies as surrogate antigens stems from the Idiotype cascade proposed by Niels Jerne (1). Accordingly, anti-Id antibodies were originally described as $A b 2 \alpha$ and $A b 2 \beta$, whereby the former does not block antigen binding and the latter can inhibit binding of the corresponding Ab1 to its antigen. This lent to the conclusion that $\mathrm{Ab} 2 \beta$ mimics structurally the antigen for Ab1. The concept and its experimental use have been extensively reviewed, $(2-5)$. Noted advantages of using anti-Ids over nominal antigens as therapeutic vaccines include difficulties to produce vaccines containing non-protein antigens. Anti-Ids can be produced that mimic lipid, carbohydrate or nucleic acid epitopes or even drugs. Tolerance to antigens is a major hurdle in vaccine development. Antibody-B Cell Receptor binding occurs at multiple sites, while antigen strictly binds to Complementary Determining Regions (CDRs) of antibodies. This allows stimulation of a broader determinate targeting antibody response that might include epitope spreading. Finally, anti-Ids can be persistent in inducing an immune response against antigens while avoiding autoimmune responses triggered by nominal antigen based vaccines (6).

A major obstacle both theoretically and practically is reconciling the immunization concept with the postulated restriction of the putative idiotypic network of natural antibody producing B cell clones (7). Natural antibodies, in the strictest sense, are constitutively produced (8), but this strict definition leaves out some polyreactive antibodies induced in marginal zone B cells and in T-cell independent responses, which can also be defined as natural antibodies in a broader sense (9-11). The gray zone of the natural antibody concept probably contains the answers to some of the paradoxes of idiotypy. Thus, several animal studies using anti-Id antibodies support their utility, as vaccines while human trials with monoclonal $A b 2 \beta$ were disappointing and have failed in later phase trials. Here, we analyze this failure and propose an alternative strategy for an idiotype-based immunotherapy. 


\section{SETTING THE STAGE FOR THE IDIOTYPE INTERACTIONS IN REGULATING AN IMMUNE RESPONSE}

In 1963 two laboratories reported evidence for a new marker on antibodies distinct from allotypes $(12,13)$. The term IDIOTYPE for determinants recognized by antibodies was adopted. Recognizing that antibodies against antibodies exist and playing a number game on the multitude of B-cells producing antibodies, Jerne concluded that there must be a functional network of idiotype (Id) and anti-idiotypes (anti-Id) (14). Thus, the idiotype network hypothesis was born. Yet, evidence was lacking for network interactions during an induced immune response and that an anti-Id response might have a regulating function. In 1972 several reports appeared on the potential of anti-Id antibodies to suppress a specific immune response (1517). Such results suggested that anti-Ids can affect an immune response, but did not establish that immune-modulation is part of an antigen-induced immune response. Two reports supported this latter premise $(17,18)$. An idiotypic cascade was perceived: $A b 1>A b 2 \beta>A b 3$. Ab3 would resemble $A b 1$ and were labeled Abl'. Jerne distinguished two types of anti-Ids $(1,14)$ : Based on this concept, $A b 2 \beta$ 's resemble structurally the antigen; thus the term Internal Image of antigen emerged as an explanation for this mimicry.

Shortly after this concept emerged several laboratories put this to the test by using $A b 2 \beta$ as antigen to induce target-specific immune responses (19-23). The dual functional property of $A b 2$ was demonstrated as either suppression (15) or induction of a specific response (24) to be dependent on the IgG-class (25). The idiotypic cascade implies that Abl used therapeutically might induce an antigen specific antibody response (26). Clinically, support for the idiotypic cascade is suggested in that patients developing low-level Human Anti-Mouse Antibody (HAMA) to a GD2 reactive Ab1 were shown to have higher longterm survival rates than those who did not $(27,28)$. GD2 is a disialoganglioside expressed on tumors of neuroectodermal origin, including human neuroblastoma and melanoma, with highly restricted expression on normal tissues, principally to the cerebellum and peripheral nerves in humans. The relatively tumor specific expression of GD2 makes it a suitable target for monoclonal antibody therapy and potentially a proving ground to probe and dissect network interactions.

The idiotype cascade has been suggested to be part of the functional utility of at least one monoclonal antibody presently approved by the US FDA [dinutuximab targeting the GD2 antigen: (29)]. The FDA approved Dinutuximab (Ch14.18, trade name Unituxin) and Dinutuximab beta (trade name Isquette), a monoclonal antibody used as a second-line treatment for children with high-risk neuroblastoma. However, differences in immune responses to Ab1 might be attributed to differences in Germline origins of the selected monoclonal Ab1 used in therapeutic application. A clinical trial with Ch14.18, a chimeric, in combination with IL-2, while showing a strong activation of antibody effector functions, did not show a better clinical outcome (30). Development of human anti-chimeric antibody (HACA) (21\% of patients) did result in strong reduction of ch14.18 levels, abrogating complement dependent cytotoxicity and antibody dependent cellular cytotoxicity (31). The monoclonal studied in Cheung et al. $(27,28)$ is of the IGVH2-9*02 germline while the ch14.18 variable region is derived from the IGHV1S135*01 germ line. Little attention is paid to such difference yet we know that no two antibodies need to be alike immunologically.

\section{LESSONS LEARNED FROM THERAPEUTIC ANTI-ID ANTIBODIES}

While the earlier anti-Id data were generated with polyclonal antibodies, later experiments used monoclonal anti-Ids $(32,33)$. The successful use of monoclonal anti-Ids as vaccines in inbred mice prompted several clinical trials with monoclonal $A b 2 \beta$ antibodies. The early studies on the immunomodulatory activities of $\mathrm{Ab} 2$, while consistently demonstrating immunological activity in animals, clinical trials with anti-Ids in the cancer space proved to be mixed (34). Herlyn and coworkers demonstrated that humoral immune reactivity against a tumor can be enhanced upon active anti-id vaccination (35). In these studies 30 patients with advanced colorectal carcinoma (CRC) were treated with alum-precipitated polyclonal goat anti-Id antibodies to monoclonal anti-CRC antibody CO17-1A (Ab1) in doses between 0.5 and $4 \mathrm{mg}$ per injection. All patients developed Ab3 with binding specificities on the surface of cultured tumor cells similar to the specificity of Ab1. Furthermore, the Ab3 competed with Ab1 for binding to CRC cells. Fractions of Ab3-containing sera obtained after elution of the serum immunoglobulin from CRC cells bound to purified tumor antigen and inhibited binding of $\mathrm{Ab} 2$ to $\mathrm{Ab} 1$. Six patients showed partial clinical remission and seven patients showed arrest of metastases following immunotherapy (35). Therefore, it was concluded that the Ab3 could share binding similarities with Ab1.

In other studies, an anti-Id vaccine to induce antiCarcinoembryonic antigen (CEA) antibodies (Ab3) was tested in non-human primates (36). CEA is a tumor marker largely utilized for the detection of minimal disease associated with colon cancer and considered a target for immunotherapy. The murine monoclonal antibody specific for CEA, was generated via hybridoma technology and selected for inhibition of the binding to CEA. These successful preclinical studies led to clinical trials in humans with CEA positive tumors (37). In this trial, 9 of 12 patients demonstrated an anti-anti-idiotypic (Ab3) response. All nine patients generated specific anti-CEA antibody demonstrated by reactivity with radiolabeled purified CEA. Toxicity was limited to local reaction with mild fever and chills. However, in all 12 patients the tumor progressed after completion of the trial. Four of seven responding patients were reported to have $\mathrm{T}$ cell responses to purified CEA suggesting that there was an antigen specific $\mathrm{T}$ cell response after immunization (37). A patent was filed for the anti-Id (Chatterjee et al. 5,977,315). Yet, a phase II trial with anti-Id did not improve relapse of tumor (38) and a phase III study with the anti-Id and 5-Fluorouracil (5-FU) did not improve the overall outcome of the study (39). In preclinical 
models CEA was found to be up-regulated after exposure of cancer cells to 5-FU (40). Therefore, the premise for combination therapy would be to increase the expression of the target antigen for $\mathrm{Ab} 3$ to bind to.

Further anti-Id-based vaccine studies in humans have included those associated with Tumor Associated Carbohydrate Antigens (TACAs), particularly the ganglioside targets GD3 and GD2. The anti-Id BEC2, a mimic for GD3, was found not to be highly immunogenic in melanoma patients suggesting adjuvants might be necessary (41-43). More recently BEC2 was considered as a therapeutic intervention in GBS by neutralizing specific pathogenic anti-ganglioside antibodies (44). The murine monoclonal anti-Id antibody $1 \mathrm{~A} 7$ (TriGem), a mimic of GD2, has been tested in pre-clinical studies and in the clinic (45). In pre-clinical studies, active immunization of mice, rabbits, and monkeys with TriGem induced polyclonal IgG anti-GD2 responses and TriGem specific $\mathrm{T}$ cell proliferative responses suggesting the generation of $\mathrm{CD} 4+\mathrm{T}$ cell help. In clinical trials, it was demonstrated that patients with advanced metastatic melanoma and patients with high-risk melanoma in the postsurgical adjuvant setting generated active immune responses against GD2 following immunization with TriGem. IgG subclasses were shown to be predominately IgG1 and IgG4, suggesting the possibility of the generation of CD4+ T cell help. Median survival was $16+$ months for 47 patients with advanced disease. Eighty-two percent of 69 patients with stage III disease were alive at a median follow up of 2 years.

An anti-Id vaccine has reached the market. Racotumomab (Vaxira) is now the first approved anti-Id vaccine-with approval in Cuba and Argentina. Vaxira was shown to increase the survival of Non-Small Cell Lung Cancer patients in recurrent or advanced stages (IIIB/IV). A phase III trial is currently ongoing (NCT01460472). The vaccine was initiated by the Center for Molecular Immunology in Havana, Cuba. Racotumomab, an $\mathrm{Ab} 2 \gamma$, was raised against the murine anti-ganglioside $\mathrm{N}$-glycolyl (NGc) GM3 (NGcGM3) (46). The safety of Racotumomab was established in several phase I trials in melanoma, breast and lung cancers $(47,48)$. In the lung trial, patients developed antibodies against NGcGM3 and had longer medium survival times (49). Results from a randomized trial with Racotumomab showed necrosis of tumor cells as a mechanism for efficacy (50).

While preclinical studies suggested that anti-Ids could mediate cellular responses, little evidence in humans demonstrates this aspect $(51,52)$. The most direct example for the activation of CD8+ Cytotoxic T Lymphocytes (CTL) involvement comes from a clinical trial testing a combination of the murine anti-id monoclonal antibodies MEL-2 and MF11-30 that are mimics of the high molecular weight melanomaassociated antigen (HMW-MAA) (53). The two anti-ids mimic two distinct epitopes of HMW-MAA. This combination called MELIMMUNE was shown to induce HLA-A2-restricted CTLs that lyse melanoma cells expressing both HLA-A2 antigen and HMW-MAA (53). Collectively, preclinical and clinical trials, albeit very limited, indicate that anti-Id vaccines can induce B and T-cell immune responses both in general terms supporting $\mathrm{CD} 4+\mathrm{T}$ cell activation for IgG production and tumor antigen specific CD8+ CTLs if the anti-Ids are properly chosen.

\section{SOLVING THE PROBLEMS WITH CURRENT ANTI-ID VACCINES}

While showing promise, to date no anti-Id-based vaccines has been approved by the US FDA for use in patients. Reasons for the failure of anti-Id vaccines against tumors are similar to generalized failures of other cancer vaccines. On the one hand it is possible that such failures reflect the patient populations used in the studies. We have now come to realize that checkpoint inhibitors are necessary to take the brakes off the immune system. On the other hand a major problem in cancer is the complexity and heterogeneity of antigen expression, the antigens that are potential targets of $\mathrm{T}$ and $\mathrm{B}-$ cells are multiple, diverse and endlessly adaptable. This reduces the ability of responding immune cells to consistently carry out their task to recognize, bind and destroy. A lesson might be forthcoming from consideration of the "normal" immune response to pathogens as many viruses, bacteria, and parasites induce a strong polyclonal B cell response, which can be crucial for early host defense against rapidly dividing microorganisms. In certain situations the response is restricted such as in HIV infections (54, 55). Interestingly, this clonal-restricted antibody response shares an idiotypic marker (56), termed $\mathrm{Ab} 2 \delta$. The polyclonal and sometimes oligoclonal antibodies in immune reactions would suggest that, in order to stimulate the polyclonal Ab1 spectrum, Ab2 should also be polyclonal. Early vaccine experiments were performed in rabbits and not subject to potential monoclonal anti-Id restrictions $(25,57)$. Later experiments suggested a strategy to simulate polyclonal immunization by combining monoclonals that are functional anti-Ids in that they compete with antigen clearly are not distinguished in their ability to activate functional $\mathrm{T}$ cell responses a priori $(53,58,59)$. Yet making a panel of hybridomas by screening and selecting only high affinity binders may not be enough to distinguish between protective and non-protective anti-Ids (59).

The advantages of polyclonal vs. monoclonal antibodies has recently been reviewed (60). Previous discussions have suggested a soluble antigen reflective of multiple epitopes can be a more potent modulator of humoral and cellular immune responses than $\mathrm{Ab} 2$ that represents a singular epitope (61). Counter arguments have been made (62). However, these arguments often neglect a possible influence of a network and the structural basis for antibody recognition. The major characteristic of polyclonal responses is their clonal and structural diversity. Multi-epitope binding increases the overall avidity to the target. For optimizing the targeting of $\mathrm{Ab} 2$ to idiotype expressing B-cell receptors all classes of anti- $\mathrm{Id},(\mathrm{Ab} 2 \alpha$, $\mathrm{Ab} 2 \beta, \mathrm{Ab} 2 \gamma$, and $\mathrm{Ab} 2 \delta$ ) should be involved. Thus, a polyclonal or oligoclonal anti-Id vaccine would improve targeting, by invoking a "normal' polyclonal immune response. Polyclonal $B$ cell response is a natural mode of an immune response in adaptive immunity. It is a practical and functionally important element of a healthy immune system, with considerable evidence to support its role in protection from at the least infectious agents. Consequently, we are proposing to change the strategy of monoclonal-based anti-Id vaccine development 
and use. Immunizing with polyclonal-based anti-Ids has the capacity to induce humoral antigen spread in patients by engaging multiple BCR's with the potential to activate both targeted and non-targeted antibody producing $\mathrm{B}$ and $\mathrm{T}$ cells. Immunizations with selected polyclonal anti-Ids to one or multiple target antigens might be a plausible strategy to amplify preexisting $\mathrm{B}$ cells and potentially preexisting $\mathrm{T}$ cell responses in addition to de novo generation of novel responses. This strategy abandons the concept that the idiotype vaccine represents the "Internal Image" of the antigen and supports our earlier suggestion of being a "Network Antigen" (63).

\section{RECIPES FOR MAKING POLYCLONAL ANTI-ID-BASED VACCINES}

A key prerequisite for an idiotypic network is poly/autoreactivity of some B cell clones. Moreover, it implies positive selection on existing variable regions for which there is evidence (6466). Positive selection of the $B$ cell repertoire has been demonstrated numerous times over a span of years (67-71) but the nature and the intensity of the self-signal define the choice between elimination, annergy and survival. This implies that a certain range of signal intensities including from existing antibody variable regions can probably recruit the emergent repertoire (7). A constant component of natural IgM would provide the necessary signal exposing idiotopes in the CDR3 regions (72), albeit other regions can be defined as idiotope containing (73), of the required concentration. The unique structures would be too dilute but those shared by a number of clones or sets of clonal products recognized cross-reactively by the same paratope would provide signal sufficient either for positive selection or for negative if the signal were too strong. Maybe this precludes the selection by too broadly distributed public idiotopes. It is interesting to speculate that every strong antibody response might temporarily provide a similar signal. During this time of optimal intensity it may recruit corresponding anti-idiotypic immature B cells. This mechanism may constitute an indirect way to elicit anti-Ids by (inadvertently) manipulating the existing natural antibody network and its capacity to recruit anti-Ids. It may reconcile the "second generation" network concept (7) with experimental induction of anti-Ids as well as introduce the notion that a set of clones rather than a single antibody may be necessary to put this machine in motion.

To stimulate and simulate a polyclonal response, Ab2s can be a mixture of monoclonal antibodies stimulating $\mathrm{B}$ and $\mathrm{T}$ cells $(53,58)$. There are examples of anti-Ids containing both $\mathrm{B}$ and $\mathrm{T}$ cell epitopes $(59,74)$. Admixing them might broaden a response. An alternative concept of inducing antibodies against multiple tumor-associated antigens is a pan-immunogen, which harbors "fuzzy" mimicking determinants to induce a polyclonal response to multiple antigens. This concept has not been developed with an Ab2-based vaccine but antigenmimicking peptides of glycans and TACA have shown such an ability in preclinical (75-80) and clinical studies (81, 82) where a carbohydrate mimetic peptide can induce polyclonal responses to two or more TACAs (81-83). This can be due both to shared epitopes as well as to a multifaceted mimotope exposing diverse antigenic determinants-a structural substrate of immunological polyspecificity.

The advantage of monoclonal antibodies over polyclonal is its consistency and excellent characterization. Monoclonals are produced by cell cultures seeded from a reference cell bank. In contrast polyclonal antibodies are derived from immunized animals producing a unique batch-specific biochemical and biophysical property. For use in humans, each batch must be validated satisfying the advertised criteria. The call for polyclonal or oligoclonal anti-Id antibodies must be answered with novel production strategies. The final step in monoclonal antibody production by hybridoma or recombinant technologies is the selection of the most potent clone or cell line. This is performed under socalled limiting dilution conditions. Suppose one reduced the stringency of selection and mixed a number of clones including ones with lower affinity. The number of antibodies in this polyclonal mix can be controlled. A master cell bank can be established, similar to the master banks in monoclonal production. However, since there is no experience with the clonal stability of cell lines growing in large cell culture tanks research will be required to maintain the original cell culture mix.

\section{COVERED IN THIS REVIEW}

1. Rationale and strategy of idiotype-based vaccines-Sections 1-5.

2. Ab1 can also be used to initiate idiotype cascades - Section 2 .

3. Lessons learned - Section 3

a. Ab3 can share binding similarities with Ab1

b. Utility in combination therapy

c. Clinically, Anti-Ids can induce B and T-cell immune responses against antigens.

4. Rational for importance of polyclonal responses - Section 4.

5. Redefining the mimetic nature of anti-Ids as network antigens - Section 4.

6. Introduction of a Master Bank for Polyclonal anti-Ids - Section 5.

\section{AUTHOR CONTRIBUTIONS}

HK originally laid out the framework and draft of this review. AP contributed to the discussion on polyclonal immunology. TK-E provided clinical assessment of previously published work. All authors contributed to the writing of the manuscript. 


\section{REFERENCES}

1. Jerne NK. Towards a network theory of the immune system. Ann Immunol. (1974) 125C:373-89.

2. Kieber-Emmons T, Monzavi-Karbassi B, Pashov A, Saha S, Murali R, Kohler H. The promise of the anti-idiotype concept. Front Oncol. (2012) 2:196. doi: 10.3389/fonc.2012. 00196

3. Ladjemi MZ. Anti-idiotypic antibodies as cancer vaccines: achievements and future improvements. Front Oncol. (2012) 2:158. doi: $10.3389 /$ fonc. 2012.00158

4. Lemke, H. Immune Response regulation by antigen receptors' clone-specific nonself parts. Front Immunol. (2018) 9:1471. doi: 10.3389/fimmu.2018.01471

5. Vazquez AM, Rodreguez-Zhurbenko N, Lopez AM. Anti-ganglioside antiidiotypic vaccination: more than molecular mimicry. Front Oncol. (2012) 2:170. doi: 10.3389/fonc. 2012.00170

6. Naveed A, Rahman SU, Arshad MI, Aslam B. Immune modulatory potential of anti-idiotype antibodies as a surrogate of foot-and-mouth disease virus antigen. mSphere. (2018) 3:e00522-18. doi: 10.1128/mSphere.00522-18

7. Varela F, Coutinho A. Second generation immune networks. Immunol Today. (1991) 12:159-66. doi: 10.1016/S0167-5699(05)80046-5

8. Baumgarth N, Waffarn EE, Nguyen TT. Natural and induced B-1 cell immunity to infections raises questions of nature versus nurture. Ann N Y Acad Sci. (2015) 1362:188-99. doi: 10.1111/nyas.12804

9. Cerutti A, Cols M, Puga I. Marginal zone B cells: virtues of innatelike antibody-producing lymphocytes. Nat Rev Immunol. (2013) 13:118-32. doi: $10.1038 /$ nri3383

10. Palm AK, Friedrich HC, Mezger A, Salomonsson M, Myers LK, Kleinau S. Function and regulation of self-reactive marginal zone B cells in autoimmune arthritis. Cell Mol Immunol. (2015) 12:493-504. doi: 10.1038/cmi.2015.37

11. Zhou Z, Niu H, Zheng YY, Morel L. Autoreactive marginal zone B cells enter the follicles and interact with $\mathrm{CD} 4+\mathrm{T}$ cells in lupus-prone mice. BMC Immunol. (2011) 12:7. doi: 10.1186/1471-2172-12-7

12. Kunkel HG, Mannik M, Williams RC. Individual antigenic specificity of isolated antibodies. Science. (1963) 140:1218-9. doi: $10.1126 /$ science. 140.3572 .1218

13. Oudin J, Michel M. [A new allotype form of rabbit serum gamma-globulins, apparently associated with antibody function and specificity]. C R Hebd Seances Acad Sci. (1963) 257:805-8.

14. Jerne NK. The immune system: a web of V-domains. Harvey Lect. (1974) 70 Series:93-110.

15. Cosenza H, Kohler H. Specific suppression of the antibody response by antibodies to receptors. Proc Natl Acad Sci USA. (1972) 69:2701-5. doi: 10.1073/pnas.69.9.2701

16. Cosenza H, Kohler $H$. Specific inhibition of plaque formation to phosphorylcholine by antibody against antibody. Science. (1972) 176:1027-9. doi: 10.1126/science.176.4038.1027

17. Hart DA, Wang AL, Pawlak LL, Nisonoff A. Suppression of idiotypic specificities in adult mice by administration of antiidiotypic antibody. J Exp Med. (1972) 135:1293-300. doi: 10.1084/jem.135.6.1293

18. Cosenza, H. Detection of anti-idiotype reactive cells in the response to phosphorylcholine. Eur J Immunol. (1976) 6:114-6. doi: 10.1002/eji.1830060208

19. Grzych JM, Capron M, Lambert PH, Dissous C, Torres S, Capron A. An anti-idiotype vaccine against experimental schistosomiasis. Nature. (1985) 316:74-6. doi: 10.1038/316074a0

20. Herlyn D, Somasundaram R, Zaloudik J, Jacob L, Harris D, Kieny MP, et al. Anti-idiotype and recombinant antigen in immunotherapy of colorectal cancer. Cell Biophys. (1994) 24-5:143-53. doi: 10.1007/BF027 89225

21. Raychaudhuri S, Saeki Y, Fuji H, Kohler H. Tumor-specific idiotype vaccines. I. Generation and characterization of internal image tumor antigen. $J$ Immunol. (1986) 137:1743-9.

22. Schreiber JR, Patawaran M, Tosi M, Lennon J, Pier GB. Anti-idiotypeinduced, lipopolysaccharide-specific antibody response to Pseudomonas aeruginosa. J Immunol. (1990) 144:1023-9.

23. Ward MM, Ward RE, Huang JH, Kohler H. Idiotope vaccine against Streptococcus pneumoniae. A precursor study. Jimmunol. (1987) 139:2775-80.
24. Trenkner E, Riblet R. Induction of antiphosphorylcholine antibody formation by anti-idiotypic antibodies. J Exp Med. (1975) 142:1121-32. doi: $10.1084 /$ jem.142.5.1121

25. Eichmann K, Rajewsky K. Induction of $\mathrm{T}$ and $\mathrm{B}$ cell immunity by anti-idiotypic antibody. Eur J Immunol. (1975) 5:661-6. doi: 10.1002/eji.1830051002

26. Forni L, Coutinho A, Kohler G, Jerne NK. IgM antibodies induce the production of antibodies of the same specificity. Proc Natl Acad Sci USA. (1980) 77:1125-8. doi: 10.1073/pnas.77.2.1125

27. Cheung NK, Cheung IY, Kushner BH, Ostrovnaya I, Chamberlain E, Kramer K, et al. Murine anti-GD2 monoclonal antibody 3F8 combined with granulocyte-macrophage colony-stimulating factor and 13-cisretinoic acid in high-risk patients with stage 4 neuroblastoma in first remission. J Clin Oncol. (2012) 30:3264-70. doi: 10.1200/JCO.2011.4 1.3807

28. Cheung NK, Guo HF, Heller G, Cheung IY. Induction of Ab3 and Ab3 antibody was associated with long-term survival after anti-G(D2) antibody therapy of stage 4 neuroblastoma. Clin Cancer Res. (2000) 6:2653-60.

29. Siebert N, Eger C, Seidel D, Juttner M, Lode HN. Validated detection of human anti-chimeric immune responses in serum of neuroblastoma patients treated with ch14.18/CHO. J Immunol Methods. (2014) 407:108-15. doi: 10.1016/j.jim.2014.04.001

30. Siebert $N$, Eger C, Seidel D, Juttner M, Zumpe M, Wegner D, et al. Pharmacokinetics and pharmacodynamics of ch14.18/CHO in relapsed/refractory high-risk neuroblastoma patients treated by long-term infusion in combination with IL-2. MAbs. (2016) 8:604-16. doi: 10.1080/19420862.2015.1130196

31. Siebert N, Troschke-Meurer S, Marx M, Zumpe M, Ehlert K, Gray J, et al. Impact of HACA on immunomodulation and treatment toxicity following ch14.18/CHO long-term infusion with interleukin-2: results from a SIOPEN phase 2 trial. Cancers. (2018) 10:E387. doi: 10.3390/cancers 10 100387

32. Kearney JF, Barletta R, Quan ZS, Quintans J. Monoclonal vs. heterogeneous anti-H-8 antibodies in the analysis of the anti-phosphorylcholine response in BALB/c mice. Eur J Immunol. (1981) 11:877-83. doi: 10.1002/eji.1830 111106

33. Wittner MK, Bach MA, Kohler H. Immune response to phosphorylcholine. IX. Characterization of hybridoma anti-TEPC15 antibodies. J Immunol. (1982) 128:595-9.

34. Herlyn D, Somasundaram R, Li W, Maruyama H. Anti-idiotype cancer vaccines: past and future. Cancer Immunol Immunother. (1996) 43:65-76. doi: $10.1007 / \mathrm{s} 002620050305$

35. Herlyn D, Wettendorff M, Schmoll E, Iliopoulos D, Schedel I, Dreikhausen $\mathrm{U}$, et al. Anti-idiotype immunization of cancer patients: modulation of the immune response. Proc Natl Acad Sci USA. (1987) 84:8055-9. doi: $10.1073 /$ pnas.84.22.8055

36. Chakraborty $\mathrm{M}$, Foon KA, Kohler $\mathrm{H}$, Bhattacharya-Chatterjee $\mathrm{M}$. Preclinical evaluation in nonhuman primates of an anti-idiotypic antibody that mimicks the carcinoembryonic antigen. J Immunother Emphasis Tumor Immunol. (1995) 18:95-103. doi: 10.1097/00002371-19950800 0-00003

37. Foon KA, Chakraborty M, John WJ, Sherratt A, Kohler H, BhattacharyaChatterjee M. Immune response to the carcinoembryonic antigen in patients treated with an anti-idiotype antibody vaccine. J Clin Invest. (1995) 96:334-42. doi: 10.1172/JCI118039

38. Posner MC, Niedzwiecki D, Venook AP, Hollis DR, Kindler HL Martin EW, et al. A phase II prospective multi-institutional trial of adjuvant active specific immunotherapy following curative resection of colorectal cancer hepatic metastases: cancer and leukemia group B study 89903. Ann Surg Oncol. (2008) 15:158-64. doi: 10.1245/s10434-00 7-9654-7

39. Chong G, Bhatnagar A, Cunningham D, Cosgriff TM, Harper PG, Steward W, et al. Phase III trial of 5-fluorouracil and leucovorin plus either $3 \mathrm{H} 1$ antiidiotype monoclonal antibody or placebo in patients with advanced colorectal cancer. Ann Oncol. (2006) 17:437-42. doi: 10.1093/annonc/mdj090

40. Aquino A, Prete SP, Guadagni F, Greiner JW, Giuliani A, Orlando L, et al. Effect of 5-fluorouracil on carcinoembryonic antigen expression and shedding at clonal level in colon cancer cells. Anticancer Res. (2000) 20:3475-84. 
41. Grant SC, Kris MG, Houghton AN, Chapman PB. Long survival of patients with small cell lung cancer after adjuvant treatment with the antiidiotypic antibody BEC2 plus Bacillus Calmette-Guerin. Clin Cancer Res. (1999) 5:1319-23.

42. McCaffery M, Yao TJ, Williams L, Livingston PO, Houghton AN, Chapman PB. Immunization of melanoma patients with BEC2 antiidiotypic monoclonal antibody that mimics GD3 ganglioside: enhanced immunogenicity when combined with adjuvant. Clin Cancer Res. (1996) 2:679-86

43. Yao TJ, Meyers M, Livingston PO, Houghton AN, Chapman PB. Immunization of melanoma patients with BEC2-keyhole limpet hemocyanin plus BCG intradermally followed by intravenous booster immunizations with BEC2 to induce anti-GD3 ganglioside antibodies. Clin Cancer Res. (1999) 5:77-81.

44. Usuki S, Taguchi K, Thompson SA, Chapman PB, Yu RK. Novel anti-idiotype antibody therapy for lipooligosaccharide-induced experimental autoimmune neuritis: use relevant to Guillain-Barre syndrome. J Neurosci Res. (2010) 88:1651-63. doi: 10.1002/jnr.22330

45. Foon KA, Lutzky J, Baral RN, Yannelli JR, Hutchins L, Teitelbaum A, et al. Clinical and immune responses in advanced melanoma patients immunized with an anti-idiotype antibody mimicking disialoganglioside GD2. J Clin Oncol. (2000) 18:376-84. doi: 10.1200/JCO.2000.18.2.376

46. Perez A, Mier ES, Vispo NS, Vazquez AM, Perez Rodriguez R. A monoclonal antibody against NeuGc-containing gangliosides contains a regulatory idiotope involved in the interaction with B and T cells. Mol Immunol. (2002) 39:103-12. doi: 10.1016/S0161-5890(02)00041-X

47. Diaz A, Alfonso M, Alonso R, Saurez G, Troche M, Catala M, et al. Immune responses in breast cancer patients immunized with an anti-idiotype antibody mimicking NeuGc-containing gangliosides. Clin Immunol. (2003) 107:80-9. doi: 10.1016/S1521-6616(03)00036-6

48. Neninger E, Diaz RM, de la Torre A, Rives R, Diaz A, Saurez G, et al. Active immunotherapy with 1E10 anti-idiotype vaccine in patients with small cell lung cancer: report of a phase I trial. Cancer Biol Ther. (2007) 6:145-50. doi: $10.4161 /$ cbt.6.2.3574

49. Hernandez AM, Toledo D, Martinez D, Grinan T, Brito V, Macias A, et al. Characterization of the antibody response against NeuGcGM3 ganglioside elicited in non-small cell lung cancer patients immunized with an anti-idiotype antibody. J Immunol. (2008) 181:6625-34. doi: 10.4049/jimmunol.181.9.6625

50. Alfonso S, Valdes-Zayas A, Santiesteban ER, Flores YI, Areces F, Hernandez $\mathrm{M}$, et al. A randomized, multicenter, placebo-controlled clinical trial of racotumomab-alum vaccine as switch maintenance therapy in advanced non-small cell lung cancer patients. Clin Cancer Res. (2014) 20:3660-71. doi: 10.1158/1078-0432.CCR-13-1674

51. Durrant LG, Buckley TJ, Denton GW, Hardcastle JD, Sewell HF, Robins RA. Enhanced cell-mediated tumor killing in patients immunized with human monoclonal antiidiotypic antibody 105AD7. Cancer Res. (1994) 54:4837-40.

52. Buckley DT, Robins AR, Durrant LG. Clinical evidence that the human monoclonal anti-idiotypic antibody 105AD7, delays tumor growth by stimulating anti-tumor T-cell responses. Hum Antibodies Hybridomas. (1995) 6:68-72. doi: 10.3233/HAB-1995-6205

53. Murray JL, Gillogly M, Kawano K, Efferson CL, Lee JE, Ross M, et al. Fine specificity of high molecular weight-melanoma-associated antigenspecific cytotoxic $\mathrm{T}$ lymphocytes elicited by anti-idiotypic monoclonal antibodies in patients with melanoma. Cancer Res. (2004) 64:5481-8. doi: 10.1158/0008-5472.CAN-04-0517

54. Muller S, Nara P, D’Amelio R, Biselli R, Gold D, Wang H, et al. Clonal patterns in the human immune response to HIV-1 infection. Int Rev Immunol. (1992) 9:1-13. doi: 10.3109/08830189209061779

55. Muller S, Wang H, Silverman GJ, Bramlet G, Haigwood N, Kohler H. B-cell abnormalities in AIDS: stable and clonally-restricted antibody response in HIV-1 infection. Scand J Immunol. (1993) 38:327-34. doi: 10.1111/j.1365-3083.1993.tb01734.x

56. Wang H, Muller S, Zolla-Pazner S, Kohler H. Human monoclonal and polyclonal anti-human immunodeficiency virus-1 antibodies share a common clonotypic specificity. Eur J Immunol. (1992) 22:1749-55. doi: $10.1002 /$ eji. 1830220713
57. Oudin J, Michel M. Idiotypy of rabbit antibodies. I. Comparison of idiotypy of antibodies against Salmonella typhi with that of antibodies against other bacteria in the same rabbits, or of antibodies against Salmonella typhi in various rabbits. J Exp Med. (1969) 130:595-617. doi: 10.1084/jem.13 0.3 .595

58. Pride MW, Shuey S, Grillo-Lopez A, Braslawsky G, Ross M, Legha SS, et al. Enhancement of cell-mediated immunity in melanoma patients immunized with murine anti-idiotypic monoclonal antibodies (MELIMMUNE) that mimic the high molecular weight proteoglycan antigen. Clin Cancer Res. (1998) 4:2363-70.

59. Raychaudhuri S, Kang CY, Kaveri SV, Kieber-Emmons T, Kohler, H. Tumor idiotype vaccines. VII Analysis and correlation of structural, idiotypic, and biologic properties of protective and nonprotective Ab2. J Immunol. (1990) 145:760-7.

60. Ascoli CA, Aggeler B. Overlooked benefits of using polyclonal antibodies. Biotechniques. (2018) 65:127-36. doi: 10.2144/btn-201 8-0065

61. Maruyama H, Zaloudik J, Li W, Sperlagh M, Koido T, Somasundaram R, et al. Cancer vaccines: single-epitope anti-idiotype vaccine versus multipleepitope antigen vaccine. Cancer Immunol Immunother. (2000) 49:123-32. doi: $10.1007 / \mathrm{s} 002620050611$

62. Bhattachary-Chatterjee M, Nath Baral R, Chatterjee SK, Das R, Zeytin $\mathrm{H}$, Chakraborty $\mathrm{M}$, et al. Counterpoint. Cancer vaccines: singleepitope anti-idiotype vaccine versus multiple-epitope antigen vaccine. Cancer Immunol Immunother. (2000) 49:133-41. doi: 10.1007/s002620 050612

63. Kohler H, Kieber-Emmons T, Srinivasan S, Kaveri S, Morrow WJ, Muller S, et al. Revised immune network concepts. Clin Immunol Immunopathol. (1989) 52:104-16. doi: 10.1016/0090-1229(89) 90197-9

64. Dietrich G, Varela FJ, Hurez V, Bouanani M, Kazatchkine MD. Selection of the expressed B cell repertoire by infusion of normal immunoglobulin $G$ in a patient with autoimmune thyroiditis. Eur J Immunol. (1993) 23:2945-50. doi: 10.1002/eji.1830231133

65. Freitas AA, Burlen O, Coutinho A. Selection of antibody repertoires by antiidiotypes can occur at multiple steps of B cell differentiation. J Immunol. (1988) 140:4097-102.

66. Freitas AA, Viale AC, Sundblad A, Heusser C, Coutinho A. Normal serum immunoglobulins participate in the selection of peripheral B-cell repertoires. Proc Natl Acad Sci USA. (1991) 88:5640-4. doi: 10.1073/pnas.88.13.5640

67. Chen X, Martin F, Forbush KA, Perlmutter RM, Kearney JF. Evidence for selection of a population of multi-reactive B cells into the splenic marginal zone. Int Immunol. (1997) 9:27-41. doi: 10.1093/intimm/9.1.27

68. Hayakawa K, Asano M, Shinton SA, Gui M, Allman D, Stewart CL, et al. Positive selection of natural autoreactive B cells. Science. (1999) 285:113-6. doi: 10.1126/science.285.5424.113

69. Townsend SE, Weintraub BC, Goodnow CC. Growing up on the streets: why B-cell development differs from T-cell development. Immunol Today. (1999) 20:217-20. doi: 10.1016/S0167-5699(98)01440-6

70. Übelhart R, Jumaa H. Autoreactivity and the positive selection of B cells. Eur J Immunol. (2015) 45:2971-7. doi: 10.1002/eji.201444622

71. Wen L, Brill-Dashoff J, Shinton SA, Asano M, Hardy RR, Hayakawa K. Evidence of marginal-zone B cell-positive selection in spleen. Immunity. (2005) 23:297-308. doi: 10.1016/j.immuni.2005.08.007

72. Lemke, H. Antigen receptor-intrinsic non-self: the key to understanding regulatory lymphocyte-mediated idiotypic control of adaptive immune responses. Critic Rev Immunol. (2016) 36:13-56. doi: 10.1615/CritRevImmunol.2016016606

73. Kieber-Emmons T, Kohler H. Towards a unified theory of immunoglobulin structure-function relations. Immunol Rev. (1986) 90:29-48. doi: 10.1111/j.1600-065X.1986.tb01476.x

74. Pride MW, Shi H, Anchin JM, Linthicum DS, LoVerde PT, Thakur A, et al. Molecular mimicry of hepatitis B surface antigen by an anti-idiotypederived synthetic peptide. Proc Natl Acad Sci USA. (1992) 89:11900-4. doi: $10.1073 /$ pnas.89.24.11900

75. Westerink MA, Giardina PC, Apicella MA, Kieber-Emmons T. Peptide mimicry of the meningococcal group C capsular polysaccharide. Proc Natl Acad Sci USA. (1995) 92:4021-5. doi: 10.1073/pnas.92.9.4021 
76. Agadjanyan M, Luo P, Westerink MA, Carey LA, Hutchins W, Steplewski Z, et al. Peptide mimicry of carbohydrate epitopes on human immunodeficiency virus. Nat Biotechnol. (1997) 15:547-51. doi: 10.1038/nbt0697-547

77. Hennings L, Artaud C, Jousheghany F, Monzavi-Karbassi B, Pashov A, KieberEmmons T. Carbohydrate mimetic peptides augment carbohydrate-reactive immune responses in the absence of immune pathology. Cancers. (2011) 3:4151-69. doi: 10.3390/cancers3044151

78. Kieber-Emmons T, Luo P, Qiu J, Chang TY, Insug O, Blaszczyk-Thurin $\mathrm{M}$, et al. Vaccination with carbohydrate peptide mimotopes promotes anti-tumor responses. Nat Biotechnol. (1999) 17:660-5. doi: 10.1038/ 10870

79. Monzavi-Karbassi B, Hennings LJ, Artaud C, Liu T, Jousheghany F, Pashov A, et al. Preclinical studies of carbohydrate mimetic peptide vaccines for breast cancer and melanoma. Vaccine. (2007) 25:3022-31. doi: 10.1016/j.vaccine.2007.01.072.Epub2007Jan26

80. Wondimu A, Zhang T, Kieber-Emmons T, Gimotty P, Sproesser K, Somasundaram R, et al. Peptides mimicking GD2 ganglioside elicit cellular, humoral and tumor-protective immune responses in mice. Cancer Immunol Immunother. (2008) 57:1079-89. doi: 10.1007/s00262-0070439-4

81. Hutchins LF, Makhoul I, Emanuel PD, Pennisi A, Siegel ER, Jousheghany F, et al. Targeting tumor-associated carbohydrate antigens: a phase I study of a carbohydrate mimetic-peptide vaccine in stage IV breast cancer subjects. Oncotarget. (2017) 8:99161-78. doi: 10.18632/oncotarget.21959

82. Makhoul I, Hutchins L, Emanuel PD, Pennisi A, Siegel E, Jousheghany F, et al. Moving a carbohydrate mimetic peptide into the clinic.
Hum Vaccin Immunother. (2015) 11:37-44. doi: 10.4161/hv. 34300

83. Luo P, Agadjanyan M, Qiu J, Westerink MA, Steplewski Z, KieberEmmons T. Antigenic and immunological mimicry of peptide mimotopes of Lewis carbohydrate antigens. Mol Immunol. (1998) 35:865-79. doi: 10.1016/S0161-5890(98)00067-4

Conflict of Interest Statement: TK-E and AP are named as inventors on an institutional patent application filled by UAMS that is related to the CMP vaccine briefly described in this manuscript. Therefore, TK-E and AP and UAMS have a potential financial interest in the vaccine described. No financial or other support of any kind has resulted from this patent application. These financial interests have been reviewed by approved supervision in accordance with the UAMS conflict of interest policies.

The remaining author declares that this research was conducted in the absence of any commercial or financial relationships that could be construed as a potential conflict of interest.

Copyright (C) 2019 Kohler, Pashov and Kieber-Emmons. This is an open-access article distributed under the terms of the Creative Commons Attribution License (CC BY). The use, distribution or reproduction in other forums is permitted, provided the original author(s) and the copyright owner(s) are credited and that the original publication in this journal is cited, in accordance with accepted academic practice. No use, distribution or reproduction is permitted which does not comply with these terms. 